\title{
ANTIOXIDATIVE EFFECTS OF $\alpha$-LIPOIC ACID IN THE BRAIN, LIVER AND KIDNEYS IN SELECTED MOUSE ORGANS EXPOSED TO ZYMOSAN
}

\author{
Zofia Goc,* AgnieszKa Greń, Edyta Kapusta, \\ Karol DziubeK and Waldemar Szaroma
}

Department of Animal Physiology and Toxicology, Institute of Biology, Pedagogical University of Cracow, Podbrzezie 3, 31-054 Cracow, Poland

(Received: January 16, 2014; accepted: January 6, 2015)

\begin{abstract}
This study investigated the role of exogenous $\alpha$-lipoic acid (ALA) in the inflammation caused by zymosan application. Seventy-two adult male white mice were divided into twelve groups: three control groups, three Zymosan groups, three ALA groups and three groups being the combination of Zymosan and ALA. In the experimental groups, the animals were decapitated after 3,6 and 24 hours after the injection. The activity of superoxide dismutase (SOD), catalase (CAT) and glutathione peroxidase (GSH-Px) were determined in the brain, liver and kidneys of the mice. After the injection of Zymosan, it was found that the activity of SOD, CAT and GSH-Px in the brain, liver and kidneys of mice was significantly lower in all time periods. The administration of ALA resulted in an opposite effect, namely, it increased the activity of the enzymes studied in the selected organs of mice. The Zymosan and ALA combination significantly inhibited the decrease in the activity of the enzymes compared with the values obtained in the groups of animals which received Zymosan only. The results of our study, using the Zymosan-induced inflammation, clearly indicate that ALA is an anti-inflammatory agent.
\end{abstract}

Keywords: Superoxide dismutase - glutathione peroxidase - catalase $-\alpha$-lipoic acid - Zymosan

\section{INTRODUCTION}

Zymosan is a substance derived from the cell wall of the yeast Saccharomyces cerevisiae and consists of protein-carbohydrate complexes. When injected into animals it induces inflammation by stimulating a wide range of inflammatory mediators. These induce activated components of the complement system, prostaglandins and leukot-

\footnotetext{
*Corresponding author; e-mail address: z.goc@vp.pl

Abbreviations: $\mathrm{ALA}=\alpha$-lipoic acid, $\mathrm{ANOVA}=$ analysis of variance, $\mathrm{BSA}=$ bovine serum albumin, b.w. $=$ body weight, $\mathrm{CAT}=$ catalase, $\mathrm{DHLA}=$ dihydrolipoic acid, $\mathrm{EDTA}=$ ethylenediaminetetra acetic acid disodium salt, GSH = reduced glutathione, $\mathrm{GSH}-\mathrm{Px}=$ glutathione peroxidase, $\mathrm{H}_{2} \mathrm{O}_{2}=$ hydrogen peroxide, $\cdot \mathrm{HO}=$ hydroxyl radical, $\mathrm{HOCl}=$ hypochlorous acid, i.p. $=$ intraperitoneal injection, $\mathrm{K}_{2} \mathrm{HPO}_{4}$ = dipotassium hydrogen phosphate, $\mathrm{KH}_{2} \mathrm{PO}_{4}=$ potassium dihydrogen phosphate, LA = DL- $\alpha-$ lipoic acid, $\mathrm{NO}=$ nitric oxide, $\mathrm{ONOO}^{-}=$peroxynitrite, $\mathrm{PUFA}=$ polyunsaturated fatty acids, $\mathrm{RNS}=$ reactive nitrogen species, $\mathrm{ROS}=$ reactive oxygen species, ${ }^{1} \mathrm{O}_{2}=$ singled oxygen, $\mathrm{SOD}=$ superoxide dismutase
} 
rienes, platelet aggregation factor, reactive oxygen species (ROS) and lysosomal enzymes $[19,39]$.

Overproduction of free radicals leads to oxidative stress which may lead to the destruction of healthy tissue. Indeed, at high concentrations and with continued exposure, ROS can damage all types of biomolecules including DNA, lipids, carbohydrates and proteins. This harmful effect is counteracted by the antioxidant action of both enzymatic, as well as, non-enzymatic antioxidants [43].

$\alpha$-Lipoic acid (ALA; 5-(1,2-dithiolan-3-yl) pentanoic acid), is a sulfur-containing fatty acid. It is found naturally in the human body at very low concentrations, primarily in the mitochondria where it helps to generate the energy that keeps us alive and functioning. ALA is a biogenic antioxidant which physiologically acts as a coenzyme in the oxidative decarboxylation of $\alpha$-keto acids, such as from pyruvate into acetylCoA [42]. The cyclic disulfide ALA is a potent free-radical scavenger that is absorbed from the diet, transported into cells, and reduced to its open chain form dihydrolipoic acid (DHLA), which has even greater antioxidant activity than ALA. Both forms can be quickly converted into each other by redox reactions [4].

ALA has scavenge numerous reactive oxygen and nitrogen species such as hydroxyl radical $(\cdot \mathrm{HO})$, hypochlorous acid $(\mathrm{HOCl})$, peroxynitrite $\left(\mathrm{ONOO}^{-}\right)$and singled oxygen $\left({ }^{1} \mathrm{O}_{2}\right)$ [33]. In addition, ALA supplement has been shown to reduce cellular injury caused by antioxidant deficiency. ALA supplementation has been demonstrated to prevent symptoms of vitamin E deficiency in mice [36], as well as, to inhibit neurotoxicity caused by GSH depletion in neuronal cells [17]. Consequently, many biological effects of ALA supplementation can be attributed to the antioxidant properties of ALA [30].

Unlike to other antioxidants, that function only in water or fatty tissues, ALA is unusual because it can work in both water and fat. This gives $\alpha$-lipoic acid an unusually broad spectrum of antioxidant action [22]. ALA has been termed the 'ideal' antioxidant, and it has been used in treating diseases in which oxidative stress plays a major role [27].

To confirm this suggestion, we decided to investigate the effect of single dose of ALA on the activity of superoxide dismutase (SOD), catalase (CAT) and glutathione peroxidase (GSH-Px) in the brain, liver and kidneys of mice that had previously been given zymosan. SOD, CAT and GSH-Px are vital components of the antioxidative barrier in animal cells. It is suggested more often now that the effectiveness of the protection of cells against the oxidative stress caused by the inflammation process depends on the activity of those enzymes.

\section{MATERIALS AND METHODS}

Seventy-two adult (4 month-old) male white mice, line Swiss, of the average body weight 27 grams, were used. All animals were obtained from the Experimental Research Laboratory of the Institute of Biology, Pedagogical University of Cracow and were housed in a well-ventilated experimental animal room under controlled 
conditions on a $12 \mathrm{~h} \mathrm{light} / 12 \mathrm{~h}$ dark cycle at $20{ }^{\circ} \mathrm{C}$ to $22{ }^{\circ} \mathrm{C}$, relative humidity $55 \% \pm 5 \%$, with free access to standard pellet diet (LMS, laboratory producing fodder for experimental animals, Motycz near Lublin) and water ad libitum.

The study comprised one control series and three series of experiments. Each series consisted of three groups of six animals each. Mice of the control groups received intraperitoneal (i.p.) $0.3 \mathrm{ml}$ of $0.9 \% \mathrm{NaCl}$ solution (Polfa, Poland) at 8.00 a.m. The experimental animals of the first series received a single injection (i.p.) of Zymosan (Sigma, St. Louis, MO) at the dose of $100 \mathrm{mg} / \mathrm{kg}$ body weight (b.w.) dissolved in $0.9 \% \mathrm{NaCl}$ solution at the same time of the day, i.e. at 8.00 a.m. The Zymosan doses were established according to other authors' suggestions [35, 44]. Mice of the second experimental series received a single injection (i.p.) of $\alpha$-lipoic acid (ALA) (Sigma, St. Louis, MO) at the dose of $100 \mathrm{mg} / \mathrm{kg} \mathrm{b.w.} \mathrm{dissolved} \mathrm{in} \mathrm{olive}$ oil at 8.00 a.m. The doses were established according to other authors' suggestions $[32,39]$. The experimental animals of the third series received simultaneously the injections (i.p.) of Zymosan at the dose of $100 \mathrm{mg} / \mathrm{kg}$ b.w. and ALA at the dose 100 $\mathrm{mg} / \mathrm{kg}$ b.w. at the same time of the day, i.e. at 8.00 a.m.

Both control and experimental animals were decapitated 3, 6, and 24 hours after the administration of $0.9 \% \mathrm{NaCl}$, Zymosan, ALA, or Zymosan and ALA combination. Before decapitation they were anesthetized by intramuscular administration of vetbutale (Biowet, Poland) at the dose of $35 \mathrm{mg} / \mathrm{kg}$ b.w. diluted with $0.9 \% \mathrm{NaCl}$ solution. The organs under investigation, that is the brain, liver and kidneys, were quickly removed.

The excised organs were homogenized in cooled to $4{ }^{\circ} \mathrm{C} 50 \mathrm{mM}$ phosphate buffer, containing $\mathrm{K}_{2} \mathrm{HPO}_{4}$ (dipotassium hydrogen phosphate) $+\mathrm{KH}_{2} \mathrm{PO}_{4}$ (potassium dihydrogen phosphate) $+0.1 \mathrm{mM}$ EDTA (ethylenediaminetetra acetic acid disodium salt) $(\mathrm{pH}=7.0)+0.1 \%$ BSA (bovine serum albumin) and then centrifuged. The obtained supernatants (tissue extracts) of brain, liver and kidneys were used for further investigations.

SOD activity was determined according to the method of Rice-Evans et al. [37]; CAT with Aebi spectrophotometry method [1]; GSH-Px with modified method of Lück [29]. Total protein concentration in the supernatants of homogenates of brain, liver and kidneys was determined by the method of Bradford [5] using bovine serum albumin as standard. The measurements of absorbance for all the analyses of the enzymes and proteins were carried with Beckman DU-650 spectrophotometer. The activity of the studied antioxidative enzymes in tissue extracts was calculated in $\mathrm{U} / \mathrm{mg}$ of protein.

The obtained results of SOD, CAT and GSH-Px activity in the brain, liver and kidneys were used to calculate the arithmetic means and standard deviations. The results were subjected to statistical verification using test " $t$ " Student-Gosset. Differences were considered statistically significant at $p<0.001$. The percentage changes in the activity of tested enzymes in the experimental groups compared to the corresponding control group were calculated. In order to estimate the obtained changes in the activity of SOD, CAT and GSH-Px in the studied organs, in all the analyzed periods of time for each experimental group, the ANOVA variance analysis 
test was performed. Differences were considered statistically significant at $p<0.05$, $\mathrm{p}<0.01$ and $\mathrm{p}<0.001$. All analyses were performed using the computer program STATISTICA 9 (StatSoft, Cracow, Poland).

\section{RESULTS}

The results concerning the activity of the antioxidant enzymes (SOD, CAT and GSH$\mathrm{Px})$ in the brain, liver and kidneys of the control and experimental animals are shown in Tables 1, 2. In comparison with the control values, the administration of Zymosan caused a statistically significant decrease in the activity of SOD in the examined organs in all the analyzed periods of time, i.e. 3, 6 and 24 hours after the injection.

Table 1

The activities of superoxide dismutase (SOD), catalase (CAT) and glutathione peroxidase (GSH-Px) in brain of 4-month-old male mice, line Swiss, 3, 6 and 24 hours after the intraperitoneal (i.p.) administration of Zymosan at the dose of $100 \mathrm{mg} / \mathrm{kg}$ body weight (b.w.), $\alpha$-lipoic acide (ALA) at dose of $100 \mathrm{mg} / \mathrm{kg}$ (b.w.) and simultaneously (i.p.) of Zymosan at the dose of $100 \mathrm{mg} / \mathrm{kg}$ (b.w.) and ALA at the dose $100 \mathrm{mg} / \mathrm{kg}$ (b.w.)

\begin{tabular}{|c|c|c|c|}
\hline \multirow{3}{*}{ Experimental groups } & \multicolumn{3}{|c|}{ The activity of antioxidant enzymes - SOD, CAT and GSH-Px in U/mg protein } \\
\hline & \multicolumn{3}{|c|}{ BRAIN } \\
\hline & SOD & CAT & GSH-Px \\
\hline $\begin{array}{l}\text { Control I } \\
\text { Zymosan after } 3 \mathrm{~h} \\
\text { test " } \mathrm{t} \text { " } \\
\alpha \text {-lipoic acid (ALA) after } 3 \mathrm{~h} \\
\text { test " } \mathrm{t} \text { " } \\
\text { Zymosan + ALA after } 3 \mathrm{~h} \\
\text { test " } \mathrm{t} \text { " }\end{array}$ & $\begin{array}{l}8.083 \pm 0.138 \\
5.700 \pm 0.110 \\
33.017 * \\
8.365 \pm 0.123 \\
3.722 * * \\
7.205 \pm 0.117 \\
11.880 *\end{array}$ & $\begin{array}{l}0.226 \pm 0.012 \\
0.134 \pm 0.006 \\
16.797 * \\
0.290 \pm 0.013 \\
9.066^{*} \\
0.185 \pm 0.010 \\
6.329^{*}\end{array}$ & $\begin{array}{c}0.028 \pm 0.003 \\
0.0135 \pm 0.001 \\
12.462^{*} \\
0.039 \pm 0.002 \\
6.873^{*} \\
0.021 \pm 0.002 \\
5.412^{*}\end{array}$ \\
\hline $\begin{array}{l}\text { Control II } \\
\text { Zymosan after } 6 \mathrm{~h} \\
\text { test " } \mathrm{t} \text { " } \\
\alpha \text {-lipoic acid (ALA) after } 6 \mathrm{~h} \\
\text { test " } \mathrm{t} \text { " } \\
\text { Zymosan + ALA after } 6 \mathrm{~h} \\
\text { test " } \mathrm{t} \text { " }\end{array}$ & $\begin{array}{l}7.997 \pm 0.159 \\
3.728 \pm 0.118 \\
52.645^{*} \\
8.157 \pm 0.094 \\
2.112 \\
5.828 \pm 0.087 \\
29.174^{*}\end{array}$ & $\begin{array}{c}0.236 \pm 0.018 \\
0.140 \pm 0.007 \\
11.887 * \\
0.370 \pm 0.031 \\
9.106^{*} \\
0.198 \pm 0.015 \\
3.853 * *\end{array}$ & $\begin{array}{c}0.027 \pm 0.004 \\
0.012 \pm 0.001 \\
8.806^{*} \\
0.030 \pm 0.002 \\
1.486 \\
0.018 \pm 0.003 \\
4.135^{* *}\end{array}$ \\
\hline $\begin{array}{l}\text { Control III } \\
\text { Zymosan after } 24 \mathrm{~h} \\
\text { test "t" } \\
\alpha \text {-lipoic acid (ALA) after } 24 \mathrm{~h} \\
\text { test "t" } \\
\text { Zymosan + ALA after } 24 \mathrm{~h} \\
\text { test "t" }\end{array}$ & $\begin{array}{l}8.014 \pm 0.147 \\
3.243 \pm 0.094 \\
66.748^{*} \\
8.089 \pm 0.103 \\
1.022 \\
5.938 \pm 0.088 \\
29.554^{*}\end{array}$ & $\begin{array}{c}0.218 \pm 0.019 \\
0.170 \pm 0.011 \\
5.189^{*} \\
0.246 \pm 0.020 \\
2.537 * * * \\
0.206 \pm 0.015 \\
1.216\end{array}$ & $\begin{array}{c}0.029 \pm 0.004 \\
0.020 \pm 0.003 \\
4.326^{* *} \\
0.028 \pm 0.002 \\
0.104 \\
0.024 \pm 0.001 \\
2.474 * * *\end{array}$ \\
\hline
\end{tabular}

* Statistically significant at $\mathrm{p}<0.001$

$* *$ Statistically significant at $\mathrm{p}<0.01$.

$* * *$ Statistically significant at $\mathrm{p}<0.05$. 


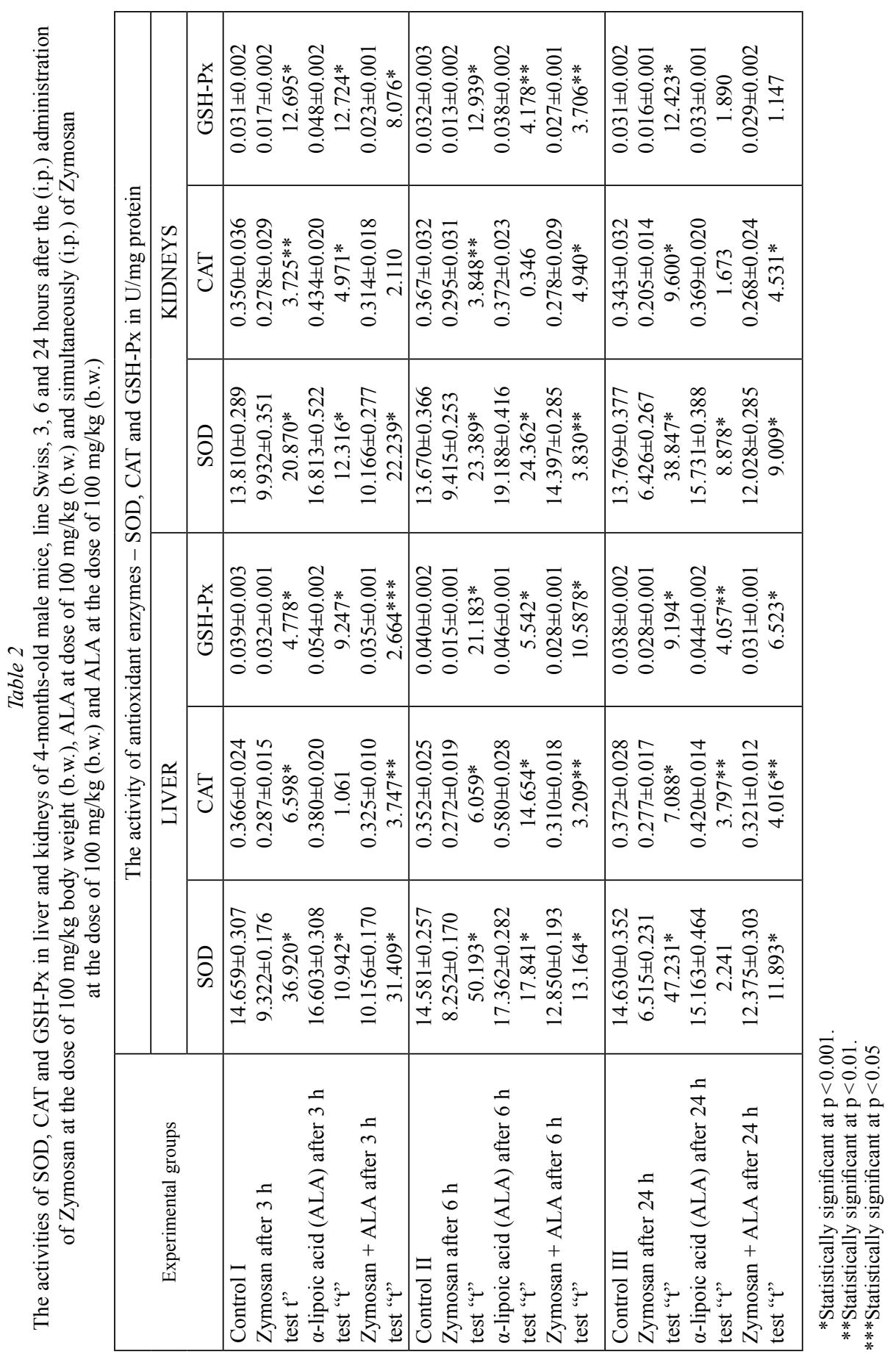


The highest decrease was observed always after $24 \mathrm{~h}$ since the beginning of the experiment, in the brain by $59.53 \%$ (Table 1 ), liver by $55.47 \%$ and kidneys by $53.33 \%$ (Table 2). The variance analysis test (ANOVA) showed that these changes in the activity of SOD were statistically significant at $\mathrm{p}<0.001$ in the brain $(\mathrm{F}(2,15)=$ $867.767)$, liver $(\mathrm{F}(2,15)=318.319)$ and kidneys $(\mathrm{F}(2,15)=248.651)$.

The injection of Zymosan also resulted in a statistically significant decrease in the activity of CAT in all investigated organs in all the analyzed periods of time. The highest decrease in the activity of CAT has been observed in the brain after 6 hours by $40.76 \%$ (Table 1), while in the liver and kidneys, after 24 hours by $25.54 \%$ and $40.24 \%$, respectively (Table 2). The variance analysis test (ANOVA) showed that the changes in the activity of CAT were statistically significant at $\mathrm{p}<0.001$ only in the brain $(\mathrm{F}(2,15)=30.057)$ and kidneys $(\mathrm{F}(2,15)=19.893)$.

We also observed a statistically significant decrease in the GSH-Px activity in all the studied groups after the Zymosan treatment. The highest percentage of changes in the activity of GSH-Px was observed in the brain after 3 hours (decrease by $57.78 \%$ ) (Table 1) and in the liver and kidneys after 6 hours by $62.19 \%$ and $58.80 \%$, respectively (Table 2). The variance analysis test (ANOVA) showed that these changes in the activity of GSH-Px were statistically significant in the brain $(\mathrm{F}(2,15)=29.011$, $\mathrm{p}<0.001)$, liver $(\mathrm{F}(2,15)=218.230, \mathrm{p}<0.001)$ and kidneys $(\mathrm{F}(2,15)=7.808, \mathrm{p}<0.01)$.

The administration of ALA caused a statistically significant increase in the activity of SOD in the brain only after 3 hours, $3.53 \%$ (Table 1). In the liver, we estimated a statistically significant increase in the activity of this enzyme after 3 and 6 hours $(13.26 \%$ and $19.07 \%)$, whereas in the kidney a significant increase was observed during all the analyzed periods of time, namely, $21.74 \%$ after 3 hours, $40.37 \%$ after 6 hours and $14.25 \%$ after 24 hours (Table 2). ANOVA showed that these changes in the activity of SOD are statistically significant at $\mathrm{p}<0.01$ in the brain $(\mathrm{F}(2,15)=10,678)$, and at $\mathrm{p}<0.001$ liver $(\mathrm{F}(2,15)=57.549)$ and kidneys $(\mathrm{F}(2,15)=94.308)$.

Furthermore, ALA induced a significant increase in the activity of CAT in the brain by $28.32 \%$ after 3 hours and $56.77 \%$ after 6 hours and $12.84 \%$ after $24 \mathrm{~h}$ since the beginning of the experiment (Table 1). Whilst, in the liver, a significant increase in the activity of this enzyme was found after $6(64.77 \%)$ and 24 hours $(12.90 \%)$ (Table 2 ). In the case of kidneys a statistically significant increase in the activity of CAT was found only after 3 hours $(24.02 \%)$ (Table 2$)$. ANOVA showed that the detected changes were statistically significant in the brain $(\mathrm{F}(2,15)=46,868)$, liver $(\mathrm{F}(2,15)=$ 143.079) and kidneys $(\mathrm{F}(2,15)=17.670)$ at $\mathrm{p}<0.001$.

Meanwhile, the administration of ALA caused a significant increase in the activity of GSH-Px in the brain only after 3 hours (Table 1), in the kidneys after 3 and 6 hours, whereas in the liver in all time partitions (Table 2). The highest percentage of changes in the analyzed organs was always observed after 3 hours since the beginning of the experiment, i.e. brain increase by $38.57 \%$, liver $-37.31 \%$ and kidneys $-53.84 \%$. ANOVA showed that these differences in the activity of GSH-Px were statistically significant at $\mathrm{p}<0.001$ in the brain $(\mathrm{F}(2,15)=38.257)$, liver $(\mathrm{F}(2,15)=35.478)$ and kidneys $(\mathrm{F}(2,15)=77.922)$. 
The simultaneous injection i.p. of Zymosan and ALA in mice caused a significant decrease is the activity of SOD in the brain and liver after 3, 6 and 24 hours after the injection, as compared to the saline-treated mice. The highest decrease in the brain by $27.13 \%$ was observed after 6 hours (Table 1) and in the case of the liver, it equalled $30.72 \%$ after 3 hours (Table 2). A statistically significant decrease in SOD activity was observed in the kidneys after $3(26.38 \%)$ and 24 hours (12.64\%) (Table 2). The variance analysis test (ANOVA) showed that these changes in the activity of SOD are statistically significant at $\mathrm{p}<0.001$ in the brain $(\mathrm{F}(2,15)=359.485)$, liver $(\mathrm{F}(2,15=$ 235.353) and kidneys $(\mathrm{F}(2,15)=337.468)$.

The administration of Zymosan and ALA caused a significant decrease in the activity of CAT in the brain only after 3 and 6 hours by $18.14 \%$ and $16.1 \%$, respectively (Table 1). In the liver, statistically significant changes of CAT were detected in all bands, but the highest decrease was recorded after 24 hours (13.71\%) (Table 2). In the case of kidneys a statistically significant decrease in the activity of CAT was found exclusively after 6 and 24 hours (24.25\% and $18.78 \%$, respectively) (Table 2). The variance analysis test (ANOVA) showed that these changes in the activity of CAT in the analyzed organs were statistically significant at $p<0.05$, only in the kidneys $(\mathrm{F}(2,15)=6.067)$.

Furthermore, the injection of Zymosan and ALA caused a significant decrease in the activity of GSH-Px in the brain and liver in all the analyzed periods. After 6 hours we observed the highest decrease of this enzyme in the brain (32.71\%) (Table 1), as well as, in the liver (30.35\%) (Table 2). In the case of kidneys, a statistically significant decrease of GSH-Px was found after 3 hours (25.64\%) and 6 hours $(15.09 \%)$. (Table 2). The variance analysis test (ANOVA) showed that these changes in the activity of GSH-Px were statistically significant in the brain $(\mathrm{F}(2,15)=8.565$, $\mathrm{p}<0.01)$, liver $(\mathrm{F}(2,15)=39.440, \mathrm{p}<0.001)$ and kidneys $(\mathrm{F}(2,15)=23.009, \mathrm{p}<0.001)$.

\section{DISCUSSION}

In the present experiments, the physiological alterations in the examined organs of mice after Zymosan and ALA administration have been shown. These changes were manifested in various activities of SOD, CAT and GSH-Px after the administration of Zymosan, ALA or Zymosan and ALA in the brain, liver and kidneys.

Antioxidant enzymes play an important role in the protection from oxidative injury to the body. One of the therapeutic approaches by which these disorders can be prevented, is the increase of the levels of SOD, CAT and, GSH-Px in the body by interventions which may include the intake increases of dietary supplements rich in antioxidants/antioxidant enzymes. Altered SOD levels and chronic inflammation have been associated with neurodegenerative diseases [26], metabolic diseases, and liver diseases [23]. SOD mainly act by quenching the superoxide $\left(\mathrm{O}_{2}{ }^{-}\right)$, CAT by catalyzing the decomposition of $\mathrm{H}_{2} \mathrm{O}_{2}$ to water and oxygen. GSH-Px is a selenium containing enzyme which catalyses the reduction of $\mathrm{H}_{2} \mathrm{O}_{2}$ and lipid hydroperoxide, generated during lipid peroxidation, to water, using reduced glutathione (GSH) as 
substrate $[25,28]$. The decreased levels of the antioxidant enzymes such as SOD CAT and GSH-Px could reflect mitochondrial dysfunction [38].

The intraperitoneal administration of Zymosan in mice leads to several illnesses in experimental animals, characterized by a systemic toxicity and significant loss of body weight. Also, Zymosan increased the production of pro-inflammatory cytokines and mediators, causing a generalized dysfunction of liver, lung and kidneys in female mice [11]. Zymosan is not degradable and its application to animals represents a new experimental shock model by acute peritonitis induction, severe hypotension, and signs of systemic illness [20]. It is a well-known fact that chronic inflammatory diseases are associated with enhanced ROS and reactive nitrogen species (RNS) production exemplified by elevated levels of $\mathrm{NO}$ and $\mathrm{H}_{2} \mathrm{O}_{2}$ in the site of inflammation [3, 13]. These oxidants can be generated by enzymes abundant not only in inflammatory cells but also in non-inflammatory cells [21].

The brain is particularly sensitive to oxidative damage. This is due to the consumption of large amounts of oxygen, a high concentration of unsaturated fatty acids and a relatively high concentration of heavy metal ions. Furthermore, the brain tissue contained a small amount of substances with antioxidant properties [7]. So, it is more susceptible to oxidative damage than other tissues $[10,15]$. In the experiment, the supply - of Zymosan resulted in a clear decrease in the activity of SOD, CAT and GSH-Px in the brain. Similar changes in these enzymes activity in the brain of mice after the lower dose of Zymosan (40 mg/kg b.w.) injection were found in earlier experiment [43]. In the same experiment, the authors observed a significant decrease in the activity of those enzymes in other organs, i.e. liver and kidney what confirms our results. The liver is the main detoxifying organ in the body, and it shows high metabolic rate and it is subjected to oxidative stress. Similarly, the abundance of polyunsaturated fatty acids (PUFA) makes the kidney an organ particularly vulnerable to ROS attack [24].

ALA feeding was shown to increase ambulant activity, mitochondrial respiration, and carnitine acetyltransferase activity, as well as, to decrease oxidative stress in old rats, increase GSH levels in aged animals what suggesting that ALA feeding increases the redox potential of cells and mitochondria [16]. Akpinar et al. [2] investigated the effect of ALA on lipid peroxidation, nitric oxide production and antioxidant systems in rats exposed to chronic restraint stress. ALA increased the activities of SOD, GSH-Px and CAT in the non-stressed and stressed rats in relation to their corresponding groups. From the results they obtained, it could be concluded that this compound has an excellent antioxidant activity. This is also confirmed by Chen et al. [8] who observed significantly increased SOD and GSH-Px activity in serum, liver and breast muscles in chickens fed with ALA. Furthermore, the concentration of glutathione (GSH) in liver, and $\alpha$-tocopherol content in leg muscle was significantly higher as compared to the control. In accordance with those studies, we also observed a statistically significant increase in the activity of CAT, SOD, and GSH-Px after ALA treatment at different time intervals for individual organs, which may be the result of their physiological functions. 
SOD and GSH-Px are parts of the enzymatic antioxidant defense systems against ROS. SOD acts as the first line of defense against oxyradicals in cells by catalyzing the dismutation of endogenous cytotoxic superoxide radicals to $\mathrm{H}_{2} \mathrm{O}_{2}$ following that GSH-Px detoxify hydrogen peroxide produced [31]. Additionally, earlier studies [18, 41] have suggested that ALA can reduce oxidized GSH and increase the GSH status, which in turn exhibits increased free radical scavenging property. Besides, the increased intracellular GSH content might activate the GSH dependent enzyme such as GSH-Px, thus preventing the accumulation of hydrogen peroxide. When GSH-Px succeeded eliminating $\mathrm{H}_{2} \mathrm{O}_{2}$ from the cell, the fallen $\mathrm{H}_{2} \mathrm{O}_{2}$ has been shown to cause activation of SOD [40]. The increase in the activities of these enzymes could indicate the positive effects of ALA on this finely balanced antioxidant system.

It should be emphasized that several other studies have also provided evidence for protective effects of ALA supplementation against oxidative tissue damage in various animal models of ischemia - reperfusion, hepatic disorders, and diabetes [6, 12]. According to Feng et al. [14] $\alpha$-lipoic acid has effects on the kidneys of diabetic rats, increasing the levels of GSH, SOD, vitamins E, and C in ALA-treated group, compared to the diabetic group. Further evidence for in vivo efficiency of ALA in inflammatory diseases is given by the fact that ALA inhibits airway inflammation in a mouse model of asthma. ALA also significantly reduced inflammatory markers, an effect most likely by attenuated NF-kB DNA-binding activity [9].

In our study, the administration of ALA and then Zymosan significantly reduced the loss of activity of SOD, CAT and GSH-Px, as compared to the mice treated with Zymosan only in relation to the control groups in all organs. The results have demonstrated an anti-inflammatory activity of ALA in mice, which had been confirmed by Zygmunt et al. [45]. ALA has decreased the count of neutrophils in a model of Zymosan-induced peritonitis and significantly inhibited early vascular permeability in the Zymosan-treated group as compared to the control group. ALA serves as a sulfane sulfur acceptor and releases it in the form of hydrogen sulfide $\left(\mathrm{H}_{2} \mathrm{~S}\right)$, which is probably responsible for its anti-inflammatory activity. Hydrogen sulfide inhibits the release of pro-inflammatory cytokines and $\mathrm{NO}^{*}$. These effects depend on the dose and rate of hydrogen sulfide release at different stages of infection. The most capable way affects low concentrations of $\mathrm{H}_{2} \mathrm{~S}$ being released slowly during a long time. It is possible that in this way hydrogen sulfide is released, which would explain the antiinflammatory action of ALA.

The results obtained from our experiments and literature data suggest that the ALA can be considered as "ideal antioxidant" with abilities to scavenge reactive species and reset antioxidant levels. ALA influences endogenous cellular antioxidant levels and probably reduces pro-inflammatory mechanisms.

\section{REFERENCES}

1. Aebi, H. E. (1984) Catalase. In: Bergmeyer, H. U. (ed.) Methods of Enzymatic Analysis. Vol. 3. Wiley, New York, pp. 273-286. 
2. Akpinar, D., Yargiçoğlu, P., Derin, N., Alicigüzel, Y., Ağar, A. (2008) The effect of lipoic acid on antioxidant status and lipid peroxidation in rats exposed to chronic restraint stress. Physiol. Res. 57, 893-901.

3. Antczak, A., Nomak, D., Shariati, B., Król, M., Piasecka, G., Kurmanowska, Z. (1997) Increased hydrogen peroxide and thiobarbituric acid reactive products in expired breath condensate of asthmatic patients. Eur. Respir. J. 10, 1235-1241.

4. Biewenga, G. P., Haenen, G. R., Bast, A. (1997) The pharmacology of the antioxidant lipoic acid. Gen. Pharmacol. 29, 315-331.

5. Bradford, M. M. (1976) A rapid and sensitive method for the quantitation of microgram quantities of protein utilizing the principle for protein-dye binding. Anal Biochem. 72, 248-254.

6. Bustamante, J., Lodge, J. K., Marcocci, L., Tritschler, H. J., Packer, L., Rihn, B. H. (1998) Alphalipoic acid in liver metabolism and disease. Free Rad. Biol. Med. 24, 1023-1039.

7. Butterfield, A. D., Reed, T., Newman, S. F., Sultana, R. (2007) Roles of amyloid $\beta$-peptide-associated oxidative stress and brain protein modifications in the pathogenesis of Alzheimer's disease and mild cognitive impairment. Free Rad. Biol. Med. 43, 658-677.

8. Chen, P., Ma, Q. G., Ji, C., Zhang, J. Y., Zhao, L. H., Zhang, Y., Jie, Y. (2011) Dietary lipoic acid influences antioxidant capability and oxidative status of broilers. Int. J. Mol. Sci. 12, 8476-8488.

9. Cho, Y. S., Lee, J., Lee, T. H., Lee, K. U., Park, J. Y., Moon, H. B. (2002) Alpha-lipoic acid inhibits airway inflammation and hyperresponsiveness in a mouse model of asthma. J. Allergy Clin. Immunol. 114, 429-435.

10. Crowford, M. A. (1993) The role of essential fatty acids in neural development implications for prenatal nutrition. Am. J. Clin. Nutr. 57 (Suppl), 703-710.

11. Dimitrova, P., Gyurkovska, V., Shalova, I., Saso, L., Ivanovska, N. (2009) Inhibition of zymosaninduced kidney dysfunction by tyrphostin AG-490. J. Inflamm. (Lond.) 6: 13. doi: 10.1186/14769255-6-13.

12. Dulundu, E., Ozel, Y., Topaloglu, U., Sehirli, O., Ercan, F., Gedik, N., Sener, G. (2007) Alpha-lipopic acid protects against hepatic ischemia-reperfusion injury in rats. Pharmacology 79, 163-170.

13. Emelyanov, A., Fedoseev, G., Abulimity, A., Rudinski, K., Fedoulov, A., Karabanov, A., Barnes, P. J. (2001) Elevated concentrations of exhaled hydrogen peroxide in asthmatic patients. Chest 120, $1136-1139$.

14. Feng, B., Yan, X. F., Xue, J. L., Xu, L., Wang, H. (2013) The protective effects of alpha-lipoic acid on kidneys in type 2 diabetic goto-kakisaki rats via reducing oxidative stress. Int. J. Mol. Sci. 14, 6746-6756.

15. Foloyd, R. A., West, M., Hensley, K. (2001) Oxidative biochemical markers; clues to understanding aging in long-lived species. Exp. Gerontol. 36, 619-640.

16. Hagen, T. M., Ingersoll, R. T., Lykkesfeldt, J., Liu, J., Wehr, C. M., Vinarsky, V., Bartholomew, J. C., Ames, A. B. (1999) (R)-alpha-lipoic acid-supplemented old rats have improved mitochondrial function, decreased oxidative damage, and increased metabolic rate. FASEB J. 13, 411-418.

17. Han, D., Sen, C. K., Roy, S., Kobayashi, M. S., Tritschler, H. J., Packer, L. (1997) Protection against glutamate-induced cytotoxicity in C6 glial cells by thiol antioxidants. Am. J. Physiol. 273, R1771R1778.

18. Han, D., Tritschler, H. J., Packer, L. (1995) $\alpha$-Lipoic acid increases intracellular glutathione in a human T-lymphocyte Jurkat cell line. Biochem. Biophys. Res. Commun. 207, 258-264.

19. Impellizzeri, D., Mazzon, E., Di Paola, R., Paterniti, I., Baramanti, P., Cuzzocrea, S. (2011) Effect of NADPH-oxidase inhibitors in the experimental model of zymosan-induced shock in mice. Free Radic. Res. 45, 820-834.

20. Jansen, M. J., Hendriks, T., Verhofstad, A. A., Lange, W., Geeraedts, L. M., Jr., Goris, R. J. (1997) Gradual development of organ damage in the murine zymosan-induced multiple organ dysfunction syndrome. Shock 8, 261-267. 
21. Janssen-Heininger, Y. M., Mossman, B. T., Heintz, N. H., Forman, H. J., Kalyanaraman, B., Finkel, T., Stamler, J. S., Rhee, S. G., van der Vliet, A. (2008) Redox-based regulation of signal transduction: principles, pitfalls, and promises. Free Radic. Biol. Med. 45, 1-17.

22. Kagan, V. E., Shvedova, A., Serbinova, E., Khan, S., Swanson, C., Powell, R., Packer, L. (1992) Dihydrolipoic - a universal antioxidant both in the membrane and in the aqueous phase. Reduction of peroxyl, ascorbyl and chromanoxyl radicals. Biochem. Pharmacol. 44, 1637-1649.

23. Kitada, M., Kume, S., Imaizumi, N., Koya, D. (2011) Resveratrol improves oxidative stress and protects against diabetic nephropathy through normalization of Mn-SOD dysfunction in AMPK/SIRT1independent pathway. Diabetes 60, 634-643.

24. Kubo, K., Saito, M., Tadocoro, T., Maekawa, A. (1997) Changes in susceptibility of tissues to lipid peroxidation after ingestion of various levels of docosahexanoic acid and vitamin E. Br. J. Nutr. 78, 655-669.

25. Le Bras, M., Clément, M. V., Pervaiz, S., Brenner, C. (2005) Reactive oxygen species and the mitochondrial signaling pathway of cell death. Histol. Histopathol. 20, 205-219.

26. Li, C., Zhou, H. M. (2011) The role of manganese superoxide dismutase in inflammation defense. Enzyme Res. 2011, 387176. doi: 10.4061/2011/387176.

27. Li, H., Gonnella, P., Safavi, F., Vessal, G., Nourbakhsh, B., Zhou, F., Zhang, G. X., Rostami, A. (2013) Low dose zymosan ameliorates both chronic and relapsing experimental autoimmune encephalomyelitis. J. Neuroimmunol. 254, 28-38.

28. Liang, H., Ran, Q., Jang, Y. C., Holstein, D., Lechleiter, J., McDonald-Marsh, T., Musatov, A., Song, W., Van Remmen, H., Richardson, A. (2009) Glutathione peroxidase 4 differentially regulates the release of apoptogenic proteins from mitochondria. Free Radic. Biol. Med. 47, 312-320.

29. Lück, H. (1962) Peroxidase. In: Bergmeyer, H. U. (ed.) Methoden der enzymatischen Analyse. Verlag Chemie GmbH, Weinheim, pp. 895-897.

30. Moini, H., Packer, L., Saris, N. E. (2002) Antioxidant and prooxidant activities of alpha-lipoic acid and dihydrolipoic acid. Toxicol. Appl. Pharmacol. 182, 84-90.

31. Mruk, D. D., Silvestrini, B., Mo, M. Y., Cheng, C. Y. (2002) Antioxidant superoxide dismutase-a review: its function, regulation in the testis, and role in male fertility. Contraception 65, 305-311.

32. Odabasoglu, F., Halici, Z., Aygun, H., Halici, M., Atalay, F., Cakir, A., Cadirci, E., Bayir, Y., Suleyman, H. (2011) $\alpha$-Lipoic acid has anti-inflammatory and anti-oxidative properties: an experimental study in rats with carrageenan-induced acute and cotton pellet-induced chronic inflammations. Br. J. Nutr. 105, 31-43.

33. Packer, L., Kraemer, K., Rimbach, G. (2001) Molecular aspects of lipoic acid in the prevention of diabetes complications. Nutrition 17, 888-895.

34. Pillai, C. K., Pillai, K. S. (2002) Antioxidants in health. Indian J. Physiol. Pharmacol. 46, 1-5.

35. Pini, M., Gove, M. E., Senello, J. A., van Baal, J. W. P. M., Chan, L., Fantuzzi, G. (2008) Role and regulation of adipokines during zymosan-induced peritoneal inflammation in mice. Endocrinology 149, 4080-4085.

36. Podda, M., Tritschler, H. J., Ulrich, H., Packer, L. (1994) Alpha-lipoic acid supplementation prevents symptoms of vitamin E deficiency. Biochem. Biophys. Res. Commun. 14, 98-104.

37. Rice-Evans, C. A., Diplock, A. T., Symons, M. C. R. (1991) Techniques in free radicals research. In: Burdon, R. H., van Knippenberg, P. H. (eds) Laboratory Techniques in Biochemistry and Molecular Biology. Elsevier, Amsterdam, London, New York, Tokyo.

38. Sahach, V. F., Kakhanovs'kyŭ, E. F., Horbovets, V. S. (2008) The mitochondrial permeability transition pore opening under oxidative stress in ischemia/reperfusion in the tissue of the lower extremities. Fiziol. Zh. 54, 47-51.

39. Santos, R. C., Moresco, R. N., Peña Rico, M. A., Susperregui, A. R., Rosa, J. L., Bartrons, R., Ventura, F., Mário, D. N., Alves, S. H., Tatsch, E., Kober, H., de Mello, R. O., Scherer, P., de Oliveira, J. R. (2012) Fructose-1, 6-bisphosphate protects against zymosan-induced acute lung injury in mice. Inflammation 35, 1198-1203. 
40. Selvakumar, E., Prahalathan, C., Mythili, Y., Varalakshmi, P. (2005) Beneficial effects of DL- $\alpha$-lipoic acid on cyclophosphamide-induced oxidative stress in mitochondrial fractions of rat testis. Chem. Biol. Interact. 152, 59-66.

41. Sen, C. K. (1997) Nutritional biochemistry of cellular glutathione. J. Nutr. Biochem. 8, 660-672.

42. Smith, A. R., Shenvi, S. V., Widlansky, M., Suh, J. H., Hagen, T. M. (2004) Lipoic acid as a potential therapy for chronic diseases associated with oxidative stress. Curr. Med. Chem. 11, 1135-1146.

43. Szaroma, W., Dziubek, K. (2011) Changes in the amount of reduced glutathione and activity of antioxidant enzymes in chosen mouse organs influenced by zymosan and melatonin administration. Acta Biol. Hung. 62, 133-141.

44. Takenaka, M., Kanada, S., Hamazaki, T., Watanabe, S. (2005) Dietary supplementation with n-3 polyunsaturated fatty acids attenuates the depression of food-motivated behavior during zymosaninduced peritonitis. Biol. Pharm. Bull. 28, 1291-1293.

45. Zygmunt, M., Dudek, M., Bilska-Wilkosz, A., Bednarski, M., Mogilski, Sz., Knutelska, J., Sapa, J. (2013) Anti-inflammatory activity of lipoic acid in mice peritonitis model. Acta Pol. Pharm. 70, 899-904. 